\title{
ECOLOGICAL STUDY OF A MEDICINAL ORCHID (SATYRIUM NEPALENSE) IN AN ALPINE MEADOW
}

\author{
Babu Ram Paudel ${ }^{1 *}$ and Brihaspati Poudel ${ }^{2}$ \\ ${ }^{1}$ Department of Botany, Prithvi Narayan Campus, Tribhuvan University, Pokhara, Nepal \\ 2Sainik Awasiya Mahabidhyala, Pokhara, Nepal \\ *For correspondence: brp2033@gmail.com
}

\begin{abstract}
Ecological study of a plant species provides a valuable insight on the current status and potential future threats of the plant species. In this study, we assessed the ecological status of a medicinal orchid, Satyrium nepalense in a pasture land distributed between the elevations of 2600-3200 $\mathrm{m}$ asl. We then assessed the current threat status of the orchid based on the standards set by the world conservation union (IUCN) red list categories and criteria version 12. Our result revealed that this orchid preferably grows in the south facing open meadow. We found that in the present condition, the population of $S$. nepalense did not fall into any threat category. Indiscriminate harvesting of this plant as a fodder together with other grasses during its flowering phase is the main future potential threat to this valuable orchid at the study site. Educating local people about the ecology and importance of this medicinal orchid could prevent its future depletion from the wild habitat.
\end{abstract}

Key words: Conservation, medicinal herb, orchids, threats.

\section{INTRODUCTION}

Orchids, the members of the family Orchidaceae: the largest, most diverse, old, and distinctive family of the flowering plants with about 763 genera and 28000 currently accepted species, constitute ca $10 \%$ of all the angiosperm (Christenhusz and Byng, 2016). They exhibit broad diversity in morphology, growth form, life history and habitat that are often associated with the variation in physiology and physiography of the habitat (Cribb et al.,2003, Zhang et.al.,2018). Orchids are easily distinguished from other flowering plants by their certain specific characters such as zygomorphic resipunate (bent back with the face upward) flowers, highly modified petals (labellum), fused stamens and carpels, and extremely small seeds. Orchids are distributed in all the climatic conditions, i.e. tropical to alpine regions, and thus exhibit one of the broadest latitudinal distribution ranges. Orchids occupy a diversity of habitats such as epiphytic, terrestrial, and subterranean forms, and are found throughout all the vegetated continents. Thus, orchids are absent only from the polar and desert regions (Chase,2005). Like habitat, orchids exhibit diversity in flowering phenology, however, the peak flowering season is between June and August with the highest number of species flowering during July, a mid-summer month. Despite the diversity of distribution, many orchids are locally distributed and generally rare (Waterman and Bidartondo, 2008).

Orchids are known to human beings since time immemorial. Orchids' blooms with mesmerizing long lasting colorful and often fragrant flowers 
have been great fascination to the scientists, nature lovers, and gardeners. Due to this specific features, orchids are widely grown across the globe as one of the precious ornamental plants (Raskoti,2009). Besides their ornamental uses, they have been extensively used in the various traditional medicine systems, as the source of food, and as raw materials for perfume manufacturing throughout the world (Pant and Raskoti, 2013). In the recent days, orchids are of great interest to the evolutionary biologists. These various usefulness of orchids have caused their overexploitation. Moreover, due to a few specific features such as exclusive reliance upon mycorrhizal fungi for seed germination, host specificity for growth (for epiphytic species), and specialized pollination system with biotic vectors orchids are vulnerable to environmental changes and human disturbances (Fay and Chase, 2009).

The orchids of Nepal constitute 506 species with 18 endemic species that are distributed in a wide range of habitats from the tropical to alpine regions (Rokaya et al. 2013). Although orchids are distributed throughout the country, the mountains of central Nepal with around $1600 \mathrm{~m}$ elevation are the hotspots (Acharya et.al.,2013). Most of the wild orchids in Nepal are under threat due to overexploitation for ornamental purposes and medicinal uses. Moreover, the habitats of orchids are under threat due to several anthropogenic activities such as illegal trade, deforestation, random construction of roads, overgrazing, forest fire, and the impact of the recent climate change (Rokaya et al. 2013). Among the known Nepalese orchids, a few species have been traditionally used for medicinal purposes (Pant and Raskoti,2013). Thus, the medicinal orchids experience great harvest pressure in their natural habitats.

Satyrium nepalense is an endangered terrestrial orchid usually found distributed between the elevations of $2400-3000 \mathrm{~m}$ asl (Mishra and Saklani,2012). It preferably grows in open meadows mixed with several grasses and other terrestrial orchids. In Nepal, two varieties of Satyrium nepalense (S. nepalense var. ciliatum) and (S. nepalense var nepalense) are distributed across the different mountains of Nepal. Among them, Satyrium nepalense var. nepalense occurs from central, western and eastern parts of Nepal between the elevations of 1000-3200 m. It grows in open moist grassland and blooms from September to December. Similarly, Satyrium nepalensis var. ciliatum (Lindl.) Hook.f. occurs in different parts of eastern and western Nepal along with Bhutan, China and India at altitudes of around $2900 \mathrm{~m}$ height in terrestrial and moist habitat (Raskoti,2009). In the traditional Nepalese medicine system such as Ayurveda and other local healing practices, this orchid is used as folk remedy against various medical ailments. Although the whole plant is used as medicine, tubers are the most used parts. They are used as antioxidants and antibacterial medicines, as a tonic, and as a remedy for different type of fevers, diarrhea, dysentery, and malaria (Mishra and Saklani,2012; Pant and Raskoti,2013). As tubers are the most extensively used parts, the whole plant is generally uprooted while harvesting. This may cause serious threat to this valuable medicinal orchid. In this study, we assessed the current ecological status and the potential future threats to this medicinal orchid in an alpine meadow. The findings of this result would provide important insights to reflect its current status and to formulate strategies for its effective conservation.

\section{MATERIALS AND METHODS}

\section{Study species and study site}

We selected Satyrium nepalense var. ciliatum (Lindl.) Hook.f. as the study species. It is a medium sized herb with 14-32 cm height, 
cylindrical stem with 2-3 leaves having with sheath. Elliptical ovate leaves $6-15 \times 2-5 \mathrm{~cm}$, acute apex, erect spike with densely several flowers, floral bracts reflexed, ovate- lanceolate and acute. Flowers rose pink, $7 \mathrm{~mm}$ across. Abaxial sepal elliptic, near apical margins finely ciliate, lateral sepals oblong-spatulate. Petals spatulate, elliptic obtuse, oblanceolate, apex dentate or incised, lip hooded, spur shorter than ovary and short column (Raskoti, 2009).

The study was conducted at Deorali pass, above Nangethati, Kaski. The study site is a large open meadow distributed from 2700 m - 3200m, and is located within the Annapurna Conservation Area. This meadow is extensively exploited by the local residents of Nangethati as a pasture land and harvesting grasses and other valuable herbs for their traditional subsistence.
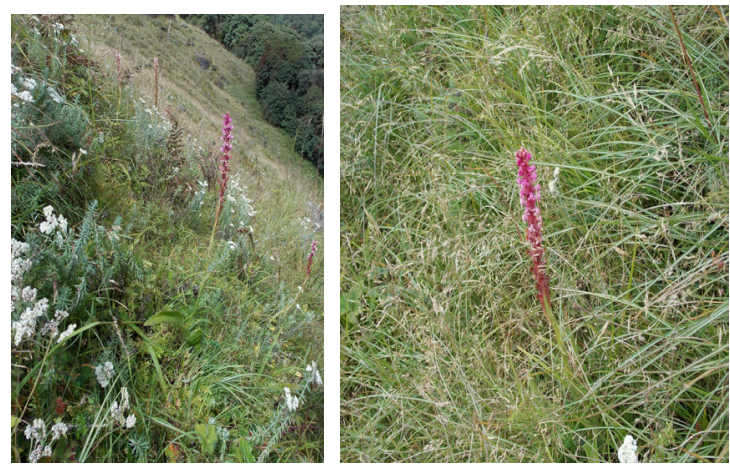

Figure 1: Satyrium nepalense var. ciliatum in its natural habitat

Ecological study

To study the ecological status of the study species, we randomly laid 12 quadrates of $20 \mathrm{~m} \times$ $20 \mathrm{~m}$ across the study sites. The quadrates were laid in a vertical/horizontal gap of $c a 100 \mathrm{~m}$ such that each elevation point (from 2700 -3200 m) contained two quadrates. Then, we estimated the frequency, density and abundance within each quadrate based on the following formula of Misra (1968). The frequency was expressed in $\%$ frequency while density and abundance were expressed in terms of plants $/ \mathrm{m}^{2}$. The differences in frequency, density and abundance along the elevation were assessed via a one-way ANOVA followed by Tukey HSD. For the graphical representation, we estimated the average value of each quantitative parameter.

Frequency $=\frac{\text { Total number of quadrats in which species occurred }}{\text { Total number of quadrats studied }} \times 100$

Density $=\frac{\text { Total number of individuals of a species in all quadrats }}{\text { Total number of quadrats studied }}$

Abundance $=\frac{\text { Total number of individuals of a species in all quadrats }}{\text { Total number of quadrats in which species occurred }}$

Then the distribution pattern was analyzed on the basis of abundance to frequency ratio following the formula.

$\frac{A}{F}$ ratio $=\frac{\text { Abundance }}{\text { Frequency }}$

The value of $\mathrm{A} / \mathrm{F}<0.025$ indicates regular, 0.026 to 0.050 as random and $>0.050$ as contiguous type of distribution (Kershaw,1973). For threat categorization, the number of matured individuals found in the study sites was used as a proxy following the standards set by IUCN red list categories and criteria version 3.1 (IUCN, 2001). An individual was considered matured if it was seen in the flowering condition. The current status and the potential future threats to this herb was then evaluated according to the standards set by IUCN red list categories and criteria, version 12 and the guidelines on using the IUCN red list categories and criteria, version 12 (IUCN, 2016). According to the IUCN criteria, if there are less than 50 matured individuals of a plant species in a population, the plant is considered as critically endangered. If the number of matured individuals in a population are less than 250 then the species is considered as endangered. If there are less than 1000 matured individuals in a population, the species is considered as vulnerable. If there are more than 1000 individuals in a population, the plant is said to be not under any threats. 


\section{RESULTS}

The habitat assessment of $S$. nepalense var. ciliatum at the study site indicated that this plant species preferably grows in an open meadow while very few individuals were found in the shaded conditions or under the tree canopy. The frequency, density, and abundance did not differ along the elevation gradients within the study site. We found that the A/F ratio was 0.0268 . This indicates the random distribution pattern of $S$. nepalense var. ciliatum at the study site. Our data revealed that the plant did not fall into any threat category as per the guidelines of IUCN. Our assessment revealed that local people does not know its medicinal uses. So, they ignored this plant, and along with other grasses of the meadow, this plant was also indiscriminately harvested for fodder. Moreover, grazing activity also exacerbated the population of this plant species.

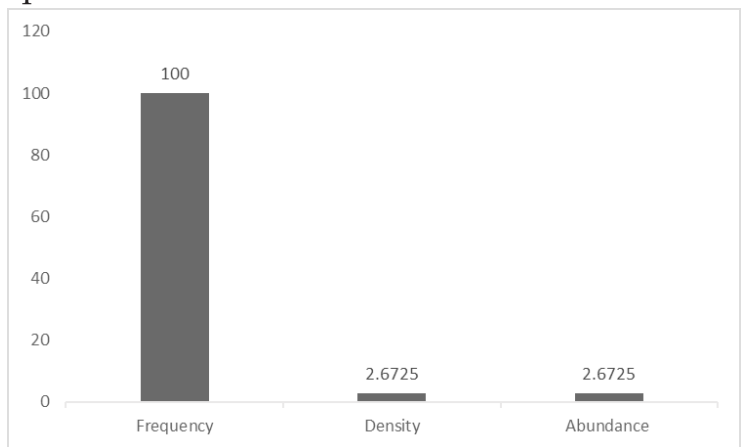

Figure 2: Ecological indicators of Satyrium nepalense var. ciliatum at the study site.

\section{DISCUSSION}

Our current result reveals that Satyrium nepalense var. ciliatum requires specific microhabitat for its propagation and growth. Higher frequency, density and abundance of this plant species in the open meadow indicates that open meadows, specifically south facing meadows are the favorable habitats of S. nepalense var. ciliatum. This plant due to its higher medicinal uses could have been under threat due to overharvesting, but as local people are not aware of its medicinal uses, the plants are never uprooted arbitrarily for the harvest of rhizome. However, local people indiscriminately cut and harvest this valuable medicinal plant as fodder to cattle. As the grass harvesting time overlaps with the flowering/early fruiting period of this plant, the indiscriminate harvesting activity would cease fruit/seed development/ dispersal, which would ultimately cause its depletion in large scale from the natural habitat. Thus, the natural means of regeneration of this valuable medicinal plant are being ceased by the human generated activities. This is a very worrying issue.

In the present context, indiscriminate harvesting of whole plant together with other grasses is the main threat to this medicinal orchid. As people are unaware of the medicinal uses, they ignore this plant as a common grass and never put effort for its conservation. As the alpine environment of the Nepalese Himalayas is experiencing general warming trend, like other alpine plant, the flowering phenology of plant may fluctuate over time which would results in reproductive failure. Thus, the current trend of global warming is likely to cause threat to this plant. However, a long term comprehensive study incorporating ecology, phenology, reproductive biology is needed to understand the potential threat of climate change to this plant species. The findings of this result provides important insights on the current status and potential threats to the genetic resources of a highly valuable medicinal plants of the alpine meadow. In the present context, educating local people about the medicinal property of this plant species could prevent the depletion of Satyrium nepalense var. ciliatum from its natural habitats. For the long term conservation of this plant species, a detailed study incorporating several ecological aspects such as habitat assessment, 
phenology, reproductive biology along its various population is required. Based on the findings of the comprehensive study, effective conservation strategies should be enforced and all the stakeholders should be committed for its conservation and sustainable uses.

\section{ACKNOWLEDGMENTS}

We express our sincere thanks to the local residents of Nangethati for their assistance during the field work. We thank Dr Mani Shrestha and anonymous reviewers for their effort to improve the presentation of the manuscript.

\section{REFERENCES}

Acharya, K.P., O.R. Vetaas, and J.B. Birks (2011). Orchid species richness along Himalayan elevational gradients. Journal of Biogeography. 38: 1821-1833.

Christenhusz, M.J.M. and J.W. Byng (2016). The number of known plant species in the world and its annual increase. Phytotaxa. 261: 201217.

Chase, M.W. (2005). Classification of Orchidaceae in the age of DNA data. Curtis's Bot. Mag. 22: 2-7.

Cribb, P.J., S.P. Kell, K.W. Dixon, R.L. Barrett (2003). Orchid conservation: a global perspective. In: Orchid conservation. Natural History Publications, Kota Kinabalu, 1-24.

Fay, M.F., M.W. Chase (2009). Orchid biology: from Linnaeus via Darwin to the 21st century. Ann. Bot. 104: 359-364.

IUCN (2001). IUCN Red List Categories and Criteria: Version 3.1., Gland, Switzerland and Cambridge, UK. Available from http:// www.iucnredlist.org/technicaldocuments/ categories-and-criteria/2001categories-criteria.
IUCN Standards and Petitions Subcommittee (2016). Guidelines for using the IUCN Red List

Categories and Criteria. Version 12. Prepared by the Standards and Petitions Subcommittee.

Kershaw, K.A (1973). Quantitative and Dynamic Plant Ecology. Edward Arnold Ltd., London.

Mishra, A.P. and S. Saklani (2012). Satyrium nepalense: a rare medicinal orchid of western himalaya (india); phytochemical screening, antimicrobial evaluation and conservation studies. Indonesian J. Pharm. 23 (3): 162 - 170.

Misra R. (1968). Ecology Work Book. Oxford and IBH Publishing Co., New Delhi.

Pant B. and B. B Raskoti (2013). Medicinal Orchids of Nepal. Himalayan Map House, Nepal

Raskoti, B.B (2009). The orchids of Nepal. Quality Printers, Nepal.

Rokaya, M. B, et.al.(2013). An annotated checklist of the orchids of Nepal. Nordic Journal of Botany.31: 511-550.

Waterman, R.J. and M.I. Bidartondo (2008). Deception above, deception below: linking pollination and mycorrhizal biology of orchids. J. Exp. Bot. 59: 1085-1096.

Zhang, S. et al. (2018). Physiological diversity of orchids. Plant Diversity 40: 196 -208 